\title{
Measuring the Economic Use Values of Recreation Resources in Protected Areas, Evidence from Nyerere National Park in Tanzania
}

\author{
Daudi Bigirwa ${ }^{*}$, Lukelo Roden Msese, Rameck Rwakalaza, Odass Bilame \\ Department of Economics, University of Dodoma, Dodoma, Tanzania \\ Email address: \\ davebigirwa@gmail.com (D. Bigirwa) \\ ${ }^{*}$ Corresponding author \\ To cite this article: \\ Daudi Bigirwa, Lukelo Roden Msese, Rameck Rwakalaza, Odass Bilame. Measuring the Economic Use Values of Recreation Resources in \\ Protected Areas, Evidence from Nyerere National Park in Tanzania. American Journal of Environmental and Resource Economics. \\ Vol. 6, No. 2, 2021, pp. 54-65. doi: 10.11648/j.ajere.20210602.14
}

Received: May 11, 2021; Accepted: May 31, 2021; Published: June 7, 2021

\begin{abstract}
Natural recreation resources play a central role in tourism activities in most part of the world as they are main source of tourist attractions. Despite this, little is known on the economic use values of natural recreation resources in Tanzania. Little information on the economic use values of natural recreational resources is attributed by market failure issues embedded with these resources as they belong to non-market goods and services which normally do not have actual market prices. In most instances these resources are considered free gifts of nature and in case they are priced their values are usually under estimated. Environmental valuation techniques can quantify the economic use value of non market goods and services such as natural recreation resources. This study employed the Individual Travel Cost Method to measure the economic use value of recreation resources in Nyerere National Park (NNP). Specifically, the study measured the consumer surplus per tourist per trip and estimated the annual recreation use value of the park. The study involved 215 tourists who were grouped into resident and non-resident tourists. Data were analyzed using STATA version 14 and a Zero Truncated Poisson Regression Model was employed to estimate tourists' demand function. The findings show that consumer surplus for resident, non-resident and when the two groups were combined together were $\$ 62.25, \$ 490.48$ and $\$ 517.01$ respectively. The annual recreation use value for resident, non-resident and both resident and non-resident tourists were respectively $\$ 89,017.5, \$ 4,255,404.48$ and $\$ 7,251,661.36$. The recreational value estimated in this study underscores the significance of conserving recreation resources in NNP. It also demonstrates that recreation activities can contribute significantly to the country economy like other economic activities thus natural recreation resources should not be underrated due to their embedded market failures. The study concludes that NNP has a significant economic value which calls for the responsible institutions in the country to properly manage the park so as to ensure a continuous flow of these benefits. Specifically, the Ministry of Natural Resources and Tourism and Tanzania National Parks could use the findings of this study to improve tourism activities in NNP and the country at large by designing sustainable nature based tourism strategies which meet tourists' preferences and country tourism goals. This will attract more tourists in the country which will increase the recreation values of NNP and other natural recreation areas.
\end{abstract}

Keywords: Protected Areas, Economic Use Value, Nature Recreation Resources, Travel Cost Method, Consumer Surplus

\section{Introduction}

\subsection{Background Information}

Tourism is a socio-cultural and economic phenomenon which involves movement of tourists to places or countries with recreation amenities for enjoyment purposes. Tourism industry is among the important sectors for the growth of country economy, especially in those countries which are gifted with natural attractions such as Tanzania [1]. Protected areas are clearly defined geographical locations which are recognized, dedicated and managed through country's legal 
systems or other effective means to achieve the long-term objectives of nature conservation with associated ecosystem services and cultural values [2]. Protected areas are endowed with natural attractions which allow establishment of tourism activities in most parts of the world [3]. In Tanzania, the industrial sector including tourism is considered as a main driver for transforming the country economy towards higher income status by the year 2025 as industries play a significant role in creating employments, increasing government revenues and foreign exchanges [4]. In Tanzanian economy, tourism industry is considered among the key sectors that generate foreign exchanges and create employments. Tourism industry contributes a significant portion to the country Gross Domestic Product (GDP), for instance in 2014 it contributed about 14\% with USD 6.7 billion, in 2017 contributed USD 2.19 billion and in 2018 it contributed $17 \%$ with USD 2.43 billion [5]. The contribution of tourism industry to Tanzanian GDP is envisaged to rise by $6.6 \%$ in each year for the next 10 years. This is attributed by the increase in number of tourist arrivals in the country, for example between 2017 and 2018 the number of tourist who visited Tanzania increased from 1.33 million to 1.49 million which is equivalent to $12.03 \%$ annual increase.

Despite the significance of tourism sector in Tanzania industrial development, little has been done on the quantification of economic use values of recreational resources in protected areas which are the main source of tourist attractions in the industry. Little evidence on the economic use values of recreational resources is due to the fact that these resources are environmental goods and services which belong to non-marketed goods and services thus they do not have actual market prices as they are not traded in normal markets [6]. Regardless the contribution of non marketed goods and services to human survival, their values are often ignored in decision making as their financial merits are not well known [7]. Unlike marketed goods such as houses, cars, clothes, timbers among others, the market cannot easily tell the price tag of most non marketed environmental goods and services in this case recreation resources. Lack of clear market prices for recreation resources might lead to either over valuation or under valuation and sometimes even abuse of these resources in protected areas of most countries [8]. Quantification of environmental resources could provide useful insights for making rational and unbiased decisions geared to efficient utilization of the same resources. In Tanzania, there are little empirical evidences on the recreation use values of protected areas such as national parks.

In order to capture the estimates of nature recreation use values, an economic valuation study on recreation resources in protected areas needs to be carried out. The market prices which are normally used to estimate the welfare are not able to quantify the welfare associated from visiting environmental amenities such as nature recreation sites. Non market valuation techniques are usually employed to quantify the recreation values of environmental amenities [9]. Economic valuation of recreation resources in protected areas provides insights on the actual and perhaps true economic use values of these resources which are drawn from a demand perspective as in most cases resource users are involved in the process. Valuation of recreational resources provides useful information for the development of appropriate policies which are geared towards improving the tourism sector. In addition, monetary estimates of nonmarketed ecosystem goods and services such as nature recreation resources support rational decisions on efficient allocation of resources among competing uses [10].

Few studies have been conducted in Tanzania on economic valuation of recreation resources in protected areas. For example studies done by Winkle; Zella and Ngunyali estimated the aggregate values of recreation uses in Arusha National Park (ANP) and Kilimanjaro National Park (KNP) respectively $[11,12]$. These studies recommended further studies to be undertaken on valuation of nature recreation resources in the country especially to those located in other parts of the country i.e Eastern, Southern or Western zones as the previous ones concentrated on the Northern Zone. Another study by Kahangwa assessed the attitude and perceptions of tourists towards wildlife based tourism in Tanzania, but the study was not able to measure the economic value of wildlife resources [5]. Thus, representative information on economic use values of nature recreation resources specifically national parks is still insufficient as recreation resources have been valued only in two national parks from the Northern side, ANP and KNP out of many protected areas in the country thus a lot is remained to be done to quantify recreation resources in other protected areas. It is against this background an economic valuation study was conducted in Nyerere National Park (NNP) to measure the use values of nature recreation resources in order to gather useful information on the park value which could guide the management and improvement of tourism activities in the park. Since establishment of NNP, there is no any study which has been done to quantify the economic use values of recreation resources in the park. Information on recreation use values of NNP is not known despite it being a largest national park in the country and Africa in particular with a size of more than 30,000 square kilometers. Missing economic use values of recreational resources in NNP might compromise the development of tourism activities in the park and Tanzania at large thus economic valuation of these resources is of paramount importance.

The objectives of this study were to measure the consumer surplus per tourist per day for visiting NNP and estimate the annual recreation use value of NNP. Contrary to previous related studies done in Tanzania where tourists were not disaggregated while estimating the national park values, this study disaggregated the tourists and calculated the consumer surplus and annual recreation values for each tourist group. In this study tourists were grouped into resident and nonresident tourists, where the former included visitors coming from East African countries including Tanzania while the latter included tourists from non-East African countries. Tourists were disaggregated so as to allow estimation of 
more realistic and relevant consumer surplus and recreation value of the park since tourists have varied socio-economic backgrounds.

\subsection{Literature Review}

\subsubsection{Travel Cost Method}

Outdoor recreation services involve the provision and use of recreation resources for enjoyment purposes [13]. Travel Cost Method (TCM) is commonly used to value non marketed goods and services associated with recreation amenities in specific sites [14]. TCM quantifies values of non marketed services (recreational sites) by using individual consumption behaviour in related markets. TCM assumes weak complementarily between the visited recreational site and the expenses incurred by individual in his or her visit. This means that when individual expenses falls to zero, the marginal utility of visitation also falls to zero, in other words the recreational is valued when the individual expenses are positive [15]. TCM investigates the real choices made by visitors in the market in this case recreation areas and establishes visitors' demand curve for recreation. The estimated demand curve reveals the tourist's willingness to pay to visit a recreation site under consideration. This means that a value of a certain recreation site is equivalent to the costs visitors have prepared and willing to pay to access the recreation amenities in that site. These costs are used as shadow prices for recreation sites and they may include total transportation expenses, site entry fees, onsite expenditures among others. Thus, the consumer surplus or access value of each visitor is computed as the difference between an individual's willingness to pay and actual travel costs incurred to visit a recreation site. This information is useful in benefit-cost analyses when evaluating the value of a recreation site against other competing uses such as mineral extraction or road construction [16]. It is also useful to estimate how a change in access to a site, such as an increase in park entrance fees, will impact demand. People are assumed to be cost sensitive, implying that the number of trips made to a recreation site decrease as travel costs increase and vice versa [7]. TCM assumptions conform with demand theory, for which higher prices of goods or services reduce the demand of those goods or services [17]. Due to budget constraints facing most economic agents, purchasing is done only for the bundle of goods that maximizes their utility [18]. Using this utility maximization approach, individual demand for recreation to a specific site is described by the following indirect utility function:

$$
\begin{array}{ll}
\text { Max } & u(T ; q \mid s, a) \\
\text { subject } & c R+q z=y
\end{array}
$$

Where $u$ is the utility derived from two different goods, $T$ is the number of days to a specific site, $q$ is the quantity of all other goods consumed, $s$ is a vector of site-specific characteristics, a individual characteristics, $\mathrm{c}$ the unit cost sustained for one day, $R$ is the number of trips to a recreation site, $z$ the composite price of all other goods and $y$ the individual income [45]. From this equation it is possible to establish a relationship between the number of days and the cost of each day which we call the demand curve:

$$
T_{i j}=f\left(C_{i}, Y_{i}, Z_{j}, A_{i}\right)
$$

From the above equation, it can be seen that the demand for recreation not only depends on the cost of the trip and the budget but also on other factors, including site-specific and individual-specific characteristics [45]. For this reason, recreational demand is often estimated including covariates of this kind in the model. Integrating the demand function below the curve and above the price it is possible to estimate the consumer surplus (CS), which is the typical welfare measure that is used to approximate the recreational value of the site [15]. Usually, what is presented in TCM analyses is the CS per trip or day, given by the negative inverse of the cost coefficient $\beta c$ of a regression [19].

TCM is divided into two different approaches, which are zonal travel cost method (ZTCM) and individual travel cost method (ITCM) [15, 43]. ZTCM groups tourists into different zones depending on the areas they are coming from and establish the visitation rate per zones and tourists' demand curve while ITCM studies each individual tourist and establish their recreational demand curve. ITCM estimates the site value using data from individual trips to same recreation site. Contrary to ZTCM, ITCM provides more information about individual consumer behaviour and most precise statistical estimates [20]. This study adopted the ITCM to gather information from individual tourists both residents and non-resident tourists who visited Nyerere National Park.

\subsubsection{The Concept of Consumer Surplus}

The idea of consumer surplus (CS) is a central tenet of the travel cost method. The importance of CS in the TCM lies in the fact that it actually represents how much a visitor values a trip or a visit to a recreational site. Therefore invariably, the CS represents the recreational use value attached to a recreational site. CS is the additive value above travel cost that individuals get by visiting a recreation site per each trip per a specified interval of time for instance in a season or a year [21]. Basing on Alfred Marshall thoughts, CS is also defined as the divergence between the actual price someone pays for some good or service and the maximum price someone would have been willing to pay for it other than do without it [22]. Alfred Marshall elucidates more on CS as the cost which someone has to pay for a thing and can never come up to what he would be willing to pay rather than go without it, so that the satisfaction he gets from its purchase generally exceeds what he gives up in paying away its price; and he thus derives from the purchase a surplus satisfaction. The excess of price which he would be willing to pay rather than going without the thing, over what he actually pays, is the economic measure of this surplus satisfaction. Following these explanations, it can intuitively be stated that the CS is the difference between the total travel costs or expenses incurred by a visitor to a recreational site and the maximum 
amount he or she was willing to spend in order to make a visit or trip [22]. The concept is shown in figure 1 below;

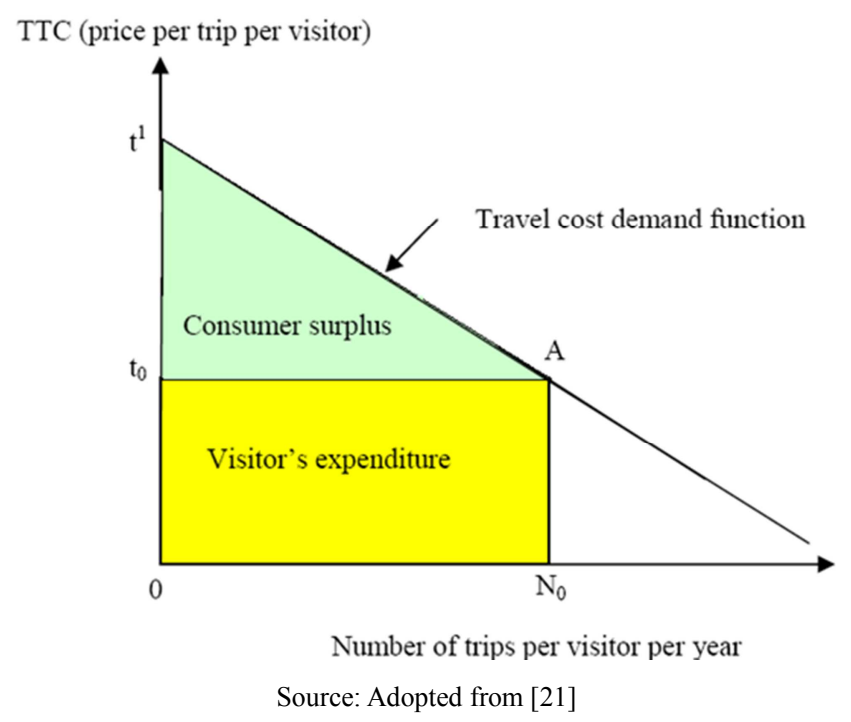

Figure 1. Travel cost demand function and consumer surplus.

Suppose we have a travel cost demand function of the functional form:

$$
T_{i j}=f\left(C_{i}, Y_{i}, Z_{j}, A_{i}\right)
$$

Where $T_{i}$ is the number of trips undertaken by individual $i$ to the recreation site within the last twelvemonths (past year), $C_{i}$ is the total travel cost (price) for visitor $i, Y_{i}$ the income level of visitor $i, \mathrm{Zj}$ is the quality of the recreational site $\mathrm{j}, \mathrm{A}_{i}$ is the individual specific characteristics.

Following Hanley and Barbie, the CS per trip is computed as follows;

$$
C S=\frac{-1}{\beta}
$$

Where $\beta$ is a coefficient of total travel cost variable obtained when maximum likelihood estimation is applied to TCM model. Note that the sign of $\beta$ is negative as it must be consistent with expectations in a demand model [14]. This implies that the CS per tourist per trip estimate is usually a positive value.

\section{Methodology}

\subsection{Study Area}

The study was conducted in Nyerere National Park (NNP) which is found in Eastern Zone of Tanzania. NNP was purposively selected because is the largest national park in the country and it is among the newly established national parks in the country as it was formed in 2019 from parts of the former Selous Game Reserve. NNP is also the largest national park in African continent. It covers an area of over 30,000 square kilometers with relatively undisturbed ecological and biological processes, including diverse range of wildlife with significant predator and prey relationship [41]. The Rufiji River which flows to Indian Ocean is found in this park with its renowned population of hippos and rhino has been designated as a photographic zone and is a popular tourist destination [41]. NNP also is endowed with outstanding number of elephants, buffalo, lion and African wild dogs.

The economic use value of recreation resources in NNP is not known, therefore this study narrowed this gap of knowledge through estimating the recreation use value of NNP. Information on the recreation use value of NNP would be instrumental in informing policy makers in tourism industry, specifically from Tanzania National Parks (TANAPA) and the Ministry of Natural Resources and Tourism (MNRT) on how to improve tourism activities in NNP and other national parks in the country. In addition, this study is furthering the recommendations given by previous studies which encouraged more valuation studies to be conducted on natural recreation resources in other parts of the country $[5,11,12]$.

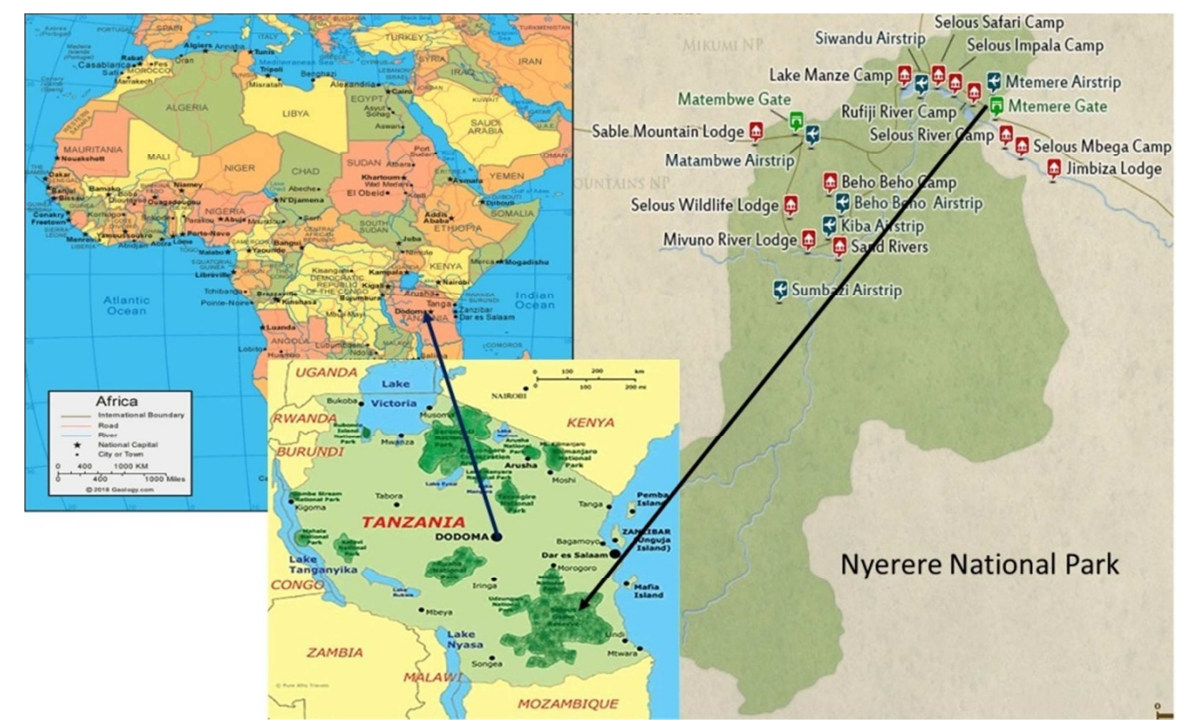

Figure2. Map of Nyerere National Park. 


\subsection{Sampling Design}

A study employed non probability sampling as it was difficult to establish a sample frame for the entire tourists who visited NNP. A convenient sampling was used to get respondents of this study which included both local and foreign tourists. However, as per the information obtained from NNP officials, visitors are categorized into two groups which are non- resident and resident tourists, in which the non-resident tourists include tourists from non- East African countries while resident tourists included tourists from East African countries, Tanzania in particular. The study adopted this categorization and used a sample size of 215 tourists of which 155 were non- residents and 60 were residents. Nonresident tourists mostly were Russians who made about $65 \%$ of the total sample size followed by Czech Republic (3.5\%), Poland (2\%), United States of America (1.5\%), United Kingdom (1.5\%), Romania (1.2\%), France (1.2\%), Slovakia $(1 \%)$, Turkish (1\%) while countries such as Spain, Switzerland, Ukraine, Serbia and Italy made less than $1 \%$. Resident tourists mostly were Kenyans who made about $8 \%$ of the total sample size while Tanzanians made only $6 \%$ of the total sample size. Purposive sampling was also employed to select key informants who were interviewed so as to enrich the information obtained from tourists.

\subsection{Data Collection Methods}

During the field semi structured questionnaires were used to collect data from tourists while an interview checklist was used to source data from key informants. Since most of tourists involved in this study were from Russia, some of the questionnaires were translated from English language into Russian in order to accommodate the Russian tourists who do not understand English. It is worth noting that NNP has two entrance gates, namely Mtemere and Matembwe, but most tourists use Mtemere gate as the park airstrip is located in this side. Therefore, in order to easily get the respondents and given the fact that most tourists who visit NNP use flights, data were collected from Mtemere gate which is the used as the main entrance of the park. Questionnaires were directly administered to tourists at the waiting area/ lounge when they were coming back from game drives or to those who were waiting for charter flights for departure. In addition to this questionnaires were also distributed to tourists who were staying in camps located inside and outside NNP. Mail interviews were also used during data collection for some tourists who requested the questionnaire to be sent to their emails. Mail questionnaire survey was opted for those tourists who claimed to be very tired as they were coming from their game drives or those who were rushing to catch up their return charter flights. Response from mail questionnaire survey was satisfactory as majority of tourists who exchanged emails sent their filled questionnaire. Secondary data on tourist information from NNP was also gathered to supplement data especially on residents' tourists. This was due to the fact that during the period of data collection few resident tourists visited NNP in comparison to non- resident tourists. In order to obtain adequate and representative sample of resident tourists, the study had to use secondary data from NNP for the past 12 months that is from December 2019 to December 2020.

\subsection{Estimation of Economic Use Value of Nyerere National Park}

In this study, tourists demand function was estimated using the number of trips travelled by tourists to NNP in the past 12 months as the dependent variable while the independent variables included the travel costs incurred by visitors during a trip to the park and visitors' socioeconomic characteristic. The trip travel cost to NNP was computed as the summation of distance cost which means the round trip cost a tourist used to travel from his/her home country to NNP [44]. This included flight costs from home country to NNP especially for foreign tourist (non- residents) and some few resident tourists from other East African countries. The travel costs also included site expenses such as game drive costs, park entrance fees also known as conservation fee, meals and accommodation costs. Following previous TCM studies, distance costs for visitors with multiple destinations (multipurpose visit) were computed by dividing their round trip distance costs to the number of site visited [23].

A Zero Truncated Poisson Regression Model was used to estimate the economic use value of NNP. The Individual Travel Cost Model (ITCM) was defined by a 'trip-generation function below [27]

$$
V=f(C, X)
$$

Where $V$ is visits made to a site, $C$ is visitation costs incurred, and $X$ is other visitors' socioeconomic variables that significantly explain $V$. In this model the dependent variable (V) is defined as the number of visits made by each visitor to a site over a specific period of time, in this case over the past 12 months. Since the dependent variable (i.e., a visit per year is a discrete parameter (count number) and follows a Poisson distribution, Poisson regression models was used in the analysis [27]. Given that Poisson distribution does not include negative integers, the mean of the expected number of visits is an exponential function of the independent variables (i.e., parameters affecting the visitation rate).

The expected trip demand function in the Poisson model was expressed as;

$$
E(y)=\exp \left(X_{i}, \beta\right)
$$

Where $E(y)$ is the expected number of visits by the tourist, $X_{i}$ is a vector of the variables affecting the number of visits, and $\beta$ is a vector of the parameters of the variables [27]. Since the value of the dependent variable (i.e., visits per year) is not zero, a zero-truncated Poisson regression model was used instead of the ordinary Poisson regression model [25]. The dependent variable of the model was the number of visits per tourist per year and the independent variables were: (1) 
Total travel costs in (USD), (2) tourist's age ( in Years), (3) tourist's sex ( $1=$ male; $0=$ female), (4) education level attained by the tourist (categorical), (5) tourists' income earning per month in (USD), (6) recreational quality of the park (1=good; $0=$ poor), (7) number of people travelled in a tourist group (8) availability of substitute recreation sites $(1=$ Yes; $0=$ No $)$.

From which, the trip demand function for the resident and non-resident tourists was specified as [24, 27];

$$
Y=\exp \left(\beta_{0}+\sum_{i=1}^{k} \beta_{i} X_{i}+\mu_{i}\right.
$$

$$
\begin{aligned}
\text { Number of visit }= & \exp \left(\beta_{0}+\beta_{1} T C+\beta_{2} \text { Age }+\beta_{3} \text { Sex }+\beta_{4}\right. \text { Education_level } \\
& +\beta_{5} \text { Income }+\beta_{6} \text { Quality }+\beta_{7} \text { People_group }+\beta_{8} \text { Sub }+\varepsilon
\end{aligned}
$$

\subsubsection{Estimation of Consumer Surplus}

From our Zero Truncated Poisson Model, the consumer surplus (CS) per tourist in each trip was calculated using equation 9 below [27];

$$
\text { CS per person per trip }=-\frac{1}{\beta T C}
$$

Where $\beta_{T C}$ is the coefficient of the tourists' travel cost variable

\subsubsection{Estimation of Annual Recreation Use Value of NNP}

The total consumer surplus (CS) per year which is equivalent to the annual recreational use value of NNP was computed by multiplying the individual consumer surplus with the total number of visits made by tourists in the past 12 months [42].

$$
\text { Recreation value }(\text { Total } C S)=-\frac{1}{\beta T C} \times \text { Total numberoftrips per year }
$$

\section{Results}

\begin{tabular}{|c|c|c|c|c|c|}
\hline Visitor type & Variable & Mean & Std. De v & Min & Max \\
\hline \multicolumn{6}{|l|}{ Residents } \\
\hline & Age & 41.41 & 7.94 & 29 & 65 \\
\hline & People in a group & 2.00 & 0.87 & 2 & 6 \\
\hline & Income & 655.20 & 263.26 & 250 & 1300 \\
\hline \multicolumn{6}{|l|}{ Non residents } \\
\hline & Age & 40.56 & 10.83 & 21 & 70 \\
\hline & People in a group & 2 & 1.44 & 1 & 11 \\
\hline & Income & 1821.71 & 1125.29 & 480 & 7500 \\
\hline \multicolumn{6}{|c|}{ Both residents and Non-residents } \\
\hline & Age & 40.80 & 10.10 & 21 & 70 \\
\hline & People in a group & 2 & 1.31 & 1 & 11 \\
\hline & Income & 1496.17 & 1097.90 & 250 & 7500 \\
\hline
\end{tabular}

\subsection{Respondents'Socio-economic Characteristics}

Table1. Sex, education and marital status of tourists.

\begin{tabular}{llll}
\hline Variable & Resident $\mathbf{n}=\mathbf{6 0}(\mathbf{\%})$ & Non Resident $\mathbf{n}=\mathbf{1 5 5}(\mathbf{\%})$ & All $\mathbf{n}=\mathbf{2 1 5}(\mathbf{\%})$ \\
\hline Sex & & & $127(59.07)$ \\
Male & $42(70.00)$ & $85(54.84)$ & $88(40.93)$ \\
Female & $18(30.00)$ & $70(45.16)$ & $9(4.33)$ \\
Education & $0(0.00)$ & $9(6.08)$ & $54(25.96)$ \\
Secondary & $16(26.67)$ & $38(25.68)$ & $92(44.23)$ \\
Diploma & $20(33.33)$ & $72(48.65)$ & $47(22.60)$ \\
Undergraduate & $24(40.00)$ & $23(15.54)$ & $6(2.88)$ \\
Masters & $0(0.00)$ & $6(4.05)$ & \\
Phd & & & \\
Marital status & $10(16.67)$ & $30(19.35)$ & \\
Single & $40(66.67)$ & $88(56.77)$ & $128(59.53)$ \\
Married & $7(11.67)$ & $14(9.03)$ & $21(9.77)$ \\
Divorced & $3(5.00)$ & $23(14.84)$ & $26(12.09)$ \\
Widow & & & \\
\hline
\end{tabular}

Table 2. Tourists' age, income and the number of people travelled in a group. 
Table 1 portrays that male tourists made a higher proportion $(59.07 \%)$ in visiting NNP than female (40.93\%). Most of the tourists who visited NNP had attained higher education of undergraduate level $(44.23 \%)$ while very few had $\mathrm{PhD}$ qualifications (2.88\%). Again, a large portion of visitors who visited NNP were married (59.53\%).

Table 2 shows that the mean age for resident and nonresident tourists who visited NNP are more less the same while average tourist income earning per month is higher for non-resident tourists (\$1821.71) than resident tourists (\$655.2). This could be due to variation in levels of economic development between the two categories of tourists, most of non-resident tourists are coming from developed countries thus they were expected to have higher per capital income in comparison to resident tourists from developing countries with high poverty levelsand low per capital income. In most instances, tourist income earning positively affects the frequency of their visitation to recreation sites.

\subsection{Description on Tourists' Travel Costs}

Table 3. Non-resident tourists' travel costs.

\begin{tabular}{|c|c|c|c|c|}
\hline Item & Mean & Standard deviation & Minimum & Maximum \\
\hline Flight costs from home country to Tanzania & $\$ 571.74$ & 262.7 & $\$ 230$ & $\$ 1430$ \\
\hline Costs from host city to NNP (charter flight, game drive vehicle, tour guide and onsite refreshments) & $\$ 308.63$ & 118.76 & $\$ 103.25$ & $\$ 880$ \\
\hline Meals and accommodation costs & $\$ 567.6$ & 425.6 & $\$ 118$ & $\$ 2468$ \\
\hline Park entrance fee (conservation fee) & $\$ 70$ & & $\$ 70$ & $\$ 70$ \\
\hline Total & $\$ 1517.97$ & & $\$ 521$ & $\$ 4848$ \\
\hline
\end{tabular}

Table 4. Resident tourists' travel costs.

\begin{tabular}{|c|c|c|c|c|}
\hline Item & Mean & Standard deviation & Minimum & Maximum \\
\hline Flight/road transport costs fornon-Tanzaniansand Tanzanians & $\$ 62.25$ & $\$ 25.52$ & $\$ 26.75$ & $\$ 108$ \\
\hline Costs for game drive vehicle, tour guide and onsite refreshments) & $\$ 90.47$ & $\$ 41.49$ & $\$ 23.33$ & $\$ 180.43$ \\
\hline Meals and accommodation costs & $\$ 43.82$ & $\$ 15.75$ & $\$ 22.6$ & $\$ 76.95$ \\
\hline TOTAL & $\$ 201.04$ & & $\$ .77 .81$ & $\$ 369.88$ \\
\hline
\end{tabular}

Table 3 and 4 summarize visitors' travel cost information. It can be seen that non -resident tourists incur more costs to visit NNP than resident tourists, with an average of \$ 1517.97 per tourist per trip. This is due to the fact that non-resident tourists are travelling from far distance in comparison to their counterparts thus they pay more costs on their flights. The costs of non -resident tourists are mostly increased by charter flight costs as most of non-resident tourists who visited NNP stay in Zanzibar so they have to hire charter flights to take them to NNP. The costs of resident tourists are almost 7.5 times less than those of non-resident tourists, with an average of \$201.04 per tourist. This is mainly due to the fact most of resident tourists do not use flights and they pay low conservation fee than the non-resident tourists. They also incur low costs in meals and accommodation as for the nonTanzanians, they do not stay in Tanzania for a long period of time when compared to non- resident tourists. Travel costs information greatly influences an individual frequency of travel to recreation sites [26].

\subsection{Recreation Demand Function for NNP}

The Poison regression model requires the mean number of trips to be exactly equal to the variance of the trips [27]. Table 5 below shows mean and variances of the number of trips made by resident and non-resident visitors in NNP.

Table 5. Mean and variances for trips made by resident and non-resident tourists in NNP.

\begin{tabular}{llll}
\hline Visitor type & Observation & Mean & Variance \\
\hline Resident tourists & 60 & 1.1667 & 0.1751 \\
Non-resident tourists & 155 & 1.1355 & 0.1828 \\
Both residents and non-resident tourists & 215 & 1.1441 & 0.1800 \\
\hline
\end{tabular}

Results in Table 5 depicts that the condition to apply Poison Model was not met as the mean number of trips were not equal to their variances, which implies that there was an over dispersion in the variance. In order to equalize the mean and variances of the number of visits made by tourists, a Zero-Truncated Poison (ZTP) regression model with vce (robust estimation) was run for the collected data. Robust estimation corrects the value of standard errors to appropriately fit this heteroskedastic model where constant variation in the error term cannot be assumed [27]. The model outcomes are presented in Table 6 below; 
Table 6. Results of Zero-Truncated Poison Regression Model.

\begin{tabular}{llll}
\hline \multirow{2}{*}{ Variables } & (Model1) & (Model2) & (Model3) \\
\cline { 2 - 4 } & Both residents and non-resident tourists & Non-resident tourists & Resident tourists \\
\hline Travel cost & $-0.00139^{* * *}$ & $-0.00204^{*}$ & -0.0160 \\
& $(0.000524)$ & $(0.00115)$ & $(0.0130)$ \\
Sex (1Male; 0female) & 0.428 & 0.368 & 0.904 \\
& $(0.398)$ & $(0.495)$ & $(1.126)$ \\
Monthly income & $0.000467^{* * *}$ & $0.000337^{* *}$ & $0.00917^{* *}$ \\
Age & $(0.000136)$ & $(0.000157)$ & $(0.00356)$ \\
Education & 0.000563 & -0.0413 & 0.0697 \\
& $(0.0196)$ & $(0.0286)$ & $(0.0660)$ \\
Number of people & 0.0585 & 0.127 & 0.0971 \\
& $(0.0753)$ & $(0.0962)$ & $(0.175)$ \\
Quality of park (1Good; 0Poor) & $-0.306^{*}$ & $-0.430^{* *}$ & 0.241 \\
& $(0.182)$ & $(0.211)$ & $(0.690)$ \\
Substitute (1Yes; 0No) & 0.291 & -0.0190 & -0.529 \\
& $(0.377)$ & $(0.472)$ & $(1.006)$ \\
Constant & $-0.965^{* *}$ & -0.738 & -0.931 \\
& $(0.382)$ & $(0.477)$ & $(1.118)$ \\
Wald chi ${ }^{2}$ (8) & -1.422 & 0.181 & -12.02 \\
Pseudo R & $(1.780)$ & $(2.432)$ & $(7.356)$ \\
Log likelihood & $46.65^{* * *}$ & $38.94 * * *$ & $70.92^{* * *}$ \\
Observations & 0.4666 & 0.5156 & 0.6667 \\
\hline
\end{tabular}

Robustst and arderrorsin parentheses

${ }^{* * *} \mathrm{p}<0.01,{ }^{* *} \mathrm{p}<0.05, * \mathrm{p}<0.1$

The results in the model variables are parallel to the theoretical expectations in TCM applications. Both models goodness of fit are well supported with high significant $(p<0.01)$. The coefficients of travel cost variables are negative in all three models, which is consistent with prior expectations. It's negative (-) value also shows that there is an opposite relation between the travel costs and the annual number of visits made by the tourists to NNP. In other words, increase in travel costs to a recreation site, reduces the number of visits made by tourists to the same site per year. Comparing the travel costs and the frequency of travel to nature recreation areas, the results are in line with the economic theory of demand, which put forward that as the price of a certain good increases, the quantity that would be bought decreases [28]. Similarly, the variable of "availability of substitute recreation site" had a negative (-) value, which means that the existence of an alternative recreation site negatively affects the number of visits made to NNP. A visitor who had an alternative visit (substitute $=1$ ) has an expected number of visit per year of $\exp (-0.965)=0.381$ that of a visitor who had no alternative site to visit (substitute $=0$ ) while holding all other variables in the model constant. Thus, substitute decreases the number of visit per year when controlling for the other variables by the factor 0.381 .

The results further portray that income had a positive influence in the number of trips made to NNP and was statistically significant for all three models. The monthly income earned by tourists had significant influence to the number of visit per year for non-resident and resident tourists at $5 \%$ significance level. Thus, high income will influence the number of trips that will be made by tourists to recreation sites. From Table 6; the expected number of visit per year changes by a factor 1.00047 (exp (0.000467)) for one-unit increase in monthly income. Other explanatory variables such as age, educational, exerted positive influence on the number of trips made per year, nevertheless their influences were not statistically significant. Correspondingly, this study found that the number of trip made in a year is affected negatively with the number of people in a tourist or family group, though the influence was not statistically significant for resident visitors.

\subsubsection{Consumer Surplus Estimates for Residents and Non-Resident Tourists}

The coefficients of travel costs obtained from ZTP models in Table 6 were used to compute the consumer surplus per trip per tourist in NNP. Consumer surplus was calculated using equation 9.

Table7. Consumer surplus for residents and non-resident tourists in NNP.

\begin{tabular}{ll}
\hline Visitor type & Consumer surplus per trip in (\$) \\
\hline Resident tourists & 62.25 \\
$\begin{array}{l}\text { Non-resident tourists } \\
\text { Both residents and non-resident } \\
\text { tourists }\end{array}$ & 490.48 \\
\hline
\end{tabular}

The consumer surplus per trip per tourist were estimated as \$ 62.25 for residents tourists and \$ 490.48 for nonresident tourists while the consumer surplus value when both tourist groups were combined together was $\$ 717.56$ [Table 7]. 


\subsubsection{Estimation of Annual Recreation Use Value of NNP}

Table 8. Annual Recreation use value of Nyerere National Park.

\begin{tabular}{llll}
\hline Visitor type & $\begin{array}{l}\text { Number of trips/ visits made } \\
\text { in a year }\end{array}$ & $\begin{array}{l}\text { Consumer surplus per trip } \\
\text { per tourist (\$) }\end{array}$ & $\begin{array}{l}\text { Annual recreation use value } \\
\text { (\$) }\end{array}$ \\
\hline Resident tourists & 1430 & 62.25 & $89,017.5$ \\
Non-resident tourists & 8676 & 490.48 & $4,255,404.48$ \\
Combined residents and non-resident tourists & 10106 & 717.56 & $7,251,661.36$ \\
\hline
\end{tabular}

Table 8 above, summarizes the annual recreation use value of NNP. It can be seen that for the past 12 months, the number of trips or visits made by tourists to NNP were 10,106 trips. The estimated consumer surplus of $\$ 717.56$ per tourist per trip yields the annual recreation use value of $\$ 7,251,661.36$ for all tourists who visited the park regardless of whether they are residents or non-residents visitors. Table 8 also shows the estimates of annual recreation use value for each category of visitors. The number of trips made by resident tourists in the past 12 months was 1430 trips which resulted into the annual recreation value of $\$ 89,017.5$ as the consumer surplus per resident tourists per trip was $\$ 62.25$. On the other hand, the annual recreation use value for nonresident tourists was $\$ 4,255,404.48$ as about 8676 trips were made in the past 12 months and the consumer surplus per non- resident tourist per trip was $\$ 490.48$. In the context of this paper, the estimated annual recreation use value for each category of visitors informs us that, nature recreation resources in NNP are most valued by non-resident tourists and they could be getting more utilities than the resident tourists.

Table 8 further portrays that the sum of annual recreation use values for each type of visitor category (\$4.344.421.98) was less than the annual recreation use value when the tourists were not categorized into groups $(\$ 7,251,661.36)$. This reveals that categorization of tourists into resident and non-resident had impact on the estimation of consumer surplus and annual recreation use values. Non categorization of visitor types in which all tourists are treated as a single group may over estimate the recreation use values as it aggregate visitors of different backgrounds and socioeconomic characteristics while categorization of tourists results into low values which seems to be more relevant and realistic. When a recreation site is receiving different types of tourists or visitors, categorization of visitor type may yield better estimates than non categorization of tourists since tourists have varied number of socio-economic characteristics.

\section{Discussion}

The estimated values of consumer surplus seem to be a bit high nevertheless environmental sites untouched by development are usually considered pristine and expected to be highly valued [2]. Therefore NNP has high consumer surplus value because it is a natural area which is considered pristine for recreation purposes with no or low economic development nearby and associated low levels of environmental pollution. The consumer surplus for visitors who visited NNP (\$717.56) contradicts with the results obtained by Zella and Ngunyali who estimated the consumer surplus of KNP to be $\$ 571.01$ [12]. The high values of consumer surplus in NNP in comparison to KNP could be attributed by the nature of tourists who visited NNP during the survey administration period. Most of the tourists included in this study were non-residents who were hosted in Zanzibar so they first arrived in Zanzibar before visiting NNP for their game drives. Movement from Zanzibar to NNP required them to use charter flights which added on their travel expenses thus increasing their park access value and consumer surplus. The same was less experienced from tourists who visited ANP, as majority of them were staying in Kilimanjaro and Arusha town thus their movement to the park involved mainly the use of vehicles instead of charter flights. This reduced their travel expenses and consumer surplus in comparison to NNP visitors. Another study estimated the economic value of Great Barrier Reef in Australia and found the consumer surplus for both local and international visitors was $\$ 800$ per tourist per trip [30].

The findings on consumer surplus value for resident tourists $(\$ 62.25)$ relates with another study done in Tanzania which estimated the consumer surplus value of $\$ 62.5$ for tourists who visited ANP from East African countries [11]. The similarity in consumer surplus value could be due to the fact that these tourists came from the same countries which do not have huge variations in their socio-economic status. Conversely, a similar study on economic valuation of flamingos in Lake Nakuru National Park in Kenya reported a higher value of consumer surplus per tourist per visit which ranged from $\$ 68$ to $\$ 85$ [31]. The consumer surplus for nature recreation among Swedish residents in Sweeden was estimated in another travel cost study and found to be $\$ 72$ per trip perperson [7]. High value of consumer surplus for local visitors who visited Lake Ziway in Ethiopia was also estimated at $\$ 81.24$ per tourist per trip [32]. A related TCM study on economic valuation of Keenjhar Lake which is the largest freshwater lake in Pakistan estimated the consumer surplus of $\$ 116$ per each visit made by the tourist [10]. On the other hand, low value of consumer surplus per day of $\$ 15$ to $\$ 25$ was estimated for freshwater beaches in Ohio [21]. This was attributed by the fact that visitors who visit beaches incur lower costs when compared to the ones who visit national parks, and most of the time people who visit beaches are locals or natives coming from nearby areas.

The estimated annual recreation value of NNP $(\$ 7,251,661.36)$ differs from the one estimated in KNP which 
was reported to be $\$ 194,000,000$ [12]. The difference could be attributed by the fact that NNP is receiving low number of visitors in comparison to KNP. Another possible reason for the difference could be that NNP is still a newly established park which is currently not known to most parts of the world. This is contrary to KNP which was established in 1973. The estimated annual recreation use value for resident tourists in this paper ( $\$ 0.895$ million) somehow relates with the recreational use value of ANP which ranged from $\$ 0.9$ million to 2.7 million [11]. This relationship is due to the fact that a study in ANP involved only resident tourists from East African countries namely Kenya, Tanzania, Uganda, Rwanda and Burundi.

The estimated annual recreation value of NNP somehow relates to other studies done outside East African countries. For instance the annual recreation value of Hamle 19 Park and Future Park in Ethiopia were estimated respectively as $\$ 453,837$ and $\$ 463,318$ [6]. Also, the recreational values of National park of Ethiopia, Kakum National Park and Wonorejo Mangrove in Indonesia were estimated and found to be $\$ 3,546,500, \$ 5,849,416$ and $\$ 421,661$ respectively [8] ,[33], [34]. In addition, Mendes and Proenca reported a recreational value of Peneda-Gerês Natural Park in Portugal to be $\$ 1,800,480$ with a consumer surplus of $\$ 148.83$ per visitor per day [35]. The annual recreation benefits of Margalla Hills National Park in Northern Pakistan were estimated at \$3,470,000 [36]. Nature areas in Sweden were estimated to have annual recreation use values of $\$ 3,406,751$ and a consumer surplus of $\$ 72$ per tourist per trip [7].

However, the findings of this study differ from those of previous works, for instance the recreation values of Virunga National Park in Congo and Kaziranga National Park in Indiawere estimated to be $\$ 48,900,000$ and $\$ 10$, 322,300 respectively [37, 38]. Another studydone in Malaysia measured the annual recreation value of Kilim Karst Geoforest Park to be $\$ 348,480,000$ and $\$ 337,154,400$ for the total travel costs and consumer surplus adjustment methods respectively [12]. Furthermore, the estimated recreation use value of Australian Alps was found to range from \$10 billion to $\$ 200$ billion [39]. More so the recreational use value of Great Barrier Reef in Australia was reported to range between $\$ 700$ million to $\$ 1.6$ billion per year [40]. The possible reason for these variations could be due to the different level of economic development and investment in tourism sector between these countries and Tanzania. These countries have relatively higher level of economic development than Tanzania and they have done more investments in their tourism industry. In comparing annual recreation values for different natural attraction areas, this paper discloses that the recreation value which is accrued from a given natural recreation area greatly depends on the level of investment which is done in that area in terms of tourism support infrastructures, facilities and human capital. The more the investments, the more the tourists will be attracted to visit that natural recreation area, thus its recreation value will automatically increase.

\section{Conclusion}

Valuation of environmental goods and services is among the major challenge for proper environmental management in most countries. This is due to the fact that these resources do not have actual market prices as they are not traded in normal markets. Pricing of these resources such as recreation resources greatly depends on human inferences through economic valuation studies using environmental valuation techniques. In Tanzania, empirical evidences show that the economic use values of recreational resources in most protected areas are not known and little has been done on quantification of these resources. Following this, the current study used Individual Travel Cost Method to measure recreation use value of NNP which is the largest national park in Tanzania and Africa in particular. Specifically, the study measured the consumer surplus per tourists per trip and estimated annual recreation use value of NNP. Contrary to other previous studies, this study disaggregated tourists into resident and non- resident tourist groups. The estimated consumer surplus per tourist per trip for resident, nonresident and both resident and non-resident tourists were respectively $\$ 62.25, \$ 490.48$ and $\$ 517.01$. The annual recreation use value for resident, non- resident and both resident and non-resident tourists were found to be $\$ 89,017.5$, $\$ 4,255,404.48$ and $\$ 7,251,661.36$ respectively. This paper confirms that NNP is highly valued by non- resident tourists in comparison to resident tourists. The study further revealed that categorization of tourists into groups (residents and nonresidents) estimated relevant and most realistic values of consumer surplus and annual recreation use value from tourists with different socio-economic backgrounds while non-categorization in which both groups of tourists were treated together resulted into high estimates. Nevertheless, recreation use value of NNP seems to be high and this could be attributed by high transportation costs incurred by tourists to reach NNP especially in hiring the charter flights.

The recreational value estimated in this study underscores the significance of conservation of recreation resources in NNP. It also proves that recreation activities can contribute significantly to the country economy like other economic activities thus they should neither be underrated nor undervalued due to market failure issues associated with natural recreation resources. This article concludes that NNP has a significant economic value which calls for proper management from responsible authorities so as to enhance the continuous flow of these benefits. The institutions responsible for tourism industry in the country, specifically the MNRT, TANAPA and TTB could use the current study findings to improve tourism activities in NNP and the country at large by designing sustainable nature based tourism strategies which meet the visitors' preferences and country's tourism goals.

\section{Recommendations}

The findings of this study have revealed that more 
recreation values are accrued from nature based recreation areas which have done more tourism investments in terms of tourism support infrastructures, facilities and human capital, vice versa is also true. For that reason, this study recommends the government of Tanzania to create more investments in tourism industry especially on the aforementioned areas. More investments in tourism industry posits that more tourists will be attracted to visit natural recreation areas in the country. This will in turn increase the recreation use value, since recreation use value greatly depends on the number of visitors who visit a certain recreation site for a specified period of time. Increase in recreation use values of recreation sites will significantly augment the contribution of tourism industry to the country economy.

The study also recommends more economic valuation studies to be done in other protected areas in the country especially the ones which are used for tourism activities. This study assumes that once a value of a given resource is recognized, resource users can act responsibly towards its proper utilization and conservation so as to enhance the continued flow of benefits from the same resource. In addition, valuation of non-marketed goods and services will minimize the abuse and misuse of these resources which in most instances are considered valueless or are undervalued.

\section{Acknowledgements}

We acknowledge the generous support from The University of Dodoma for funding this study under the Junior Academic Staff (JAS) Research Grants. However, thoughts articulated in this article are not from the University of Dodoma. Any error (s) or omission (s) which may be encountered in this paper will remain to be authors' mistake. We also appreciate the cooperation from the Tanzania Commission of Science and Technology (COSTECH), Tanzania Wildlife Research Institute (TAWIRI) and TANAPA for granting us all the required research permits for this study. We are also thankful to NNP officials for their great cooperation during and after the field study. Lastly but not least in importance, we would like to express our sincere gratitude to all resident and non-resident tourists who took part in this study.

\section{References}

[1] Mtengwa, B. A. and Malleo, J. A. (2018). Role of Tourism in Tanzania's Economic Development. International Journal of Academic Research in Economics and Management Sciences, 7 (4) 21-31.

[2] Shrestha, R. K., Stein, T. V., and Clark, J. (2007). Valuing nature-based recreation in public natural areas of the Apalachicola River region, Florida. Journal of Environmental Management, 85 (4), 977-985. Retrieved from http://www.sciencedirect.com/science/article/pii/S030147970 6003689

[3] Okello, M. M. (2005). Land Use Changes and Human-
Wildlife Conflicts in the Amboseli Area, Kenya. Human Dimensions of Wildlife 10 (1): 19-28.

[4] Mufuruki, A., Mawji, R., Marwa, M. and Kasiga, G. (2017). Tanzania's Industrialization Journey, 2016-2056: From An Agrarian to a Modern Industrialized State in Forty Years, Moran (E, E.) Publishers Limited, Nairobi, Kenya.

[5] Kahangwa, P. N (2018). Attitude and Perception of Tourists Towards Wildlife-Based Tourism in Tanzania: A Case Study Of The Northern Tourist Circuit. A Dissertation Submitted in Partial Fulfillment of the Requirements for the Degree of Master of Science in Wildlife Management and Conservation of Sokoine University of Agriculture. Morogoro, Tanzania

[6] Kassaye, T. A. (2017). Estimating the Recreational Values of Addis Ababa Parks Using the Travel Cost Method: The Case of Hamle 19 and Future Parks. World Science News 62: 124-135.

[7] Ezebilo, E. E. (2016). Economic value of a non-market ecosystem service: an application of the travel cost method to nature recreation in Sweden. International Journal of Biodiversity Science, Ecosystem Services \& Management, 12 (4): 314-327.

[8] Mossie, H., Adem, M. and Aynalem, M. (2019). Review on Economic valuation and conservation of national park of Ethiopia. The International Journal of Business Management and Technology, Vol 3 (1).

[9] Martínez-Espiñeira, R. R., and Amoako-Tuffour, J. J. (2008). Recreation demand analysis under truncation, over dispersion, and endogenous stratification: An application to Gros Morne National Park. Journal of environmental management, 88 (4), $13-13$.

[10] Dehlavi, A., and Adil, I. H. (2011). Valuing the Recreational Uses of Pakistan's Wetlands: An Application of the Travel Cost Method. South Asian Network for Development and Environmental Economics (SANDEE).

[11] Winkle, C. V (2013). African Parks; African People. An Economic Analysis of Local Tourism in Arusha National Park. Masters project submitted in partial fulfillment of the requirements for the Master of Environmental Management degree in the Nicholas School of the Environment of Duke University.

[12] Zella, A. Y, and Ngunyali, R. H, (2016). Economic Valuation of Recreation Use Value of Kilimanjaro National Park, Tanzania. J Ecosys Ecograph 6: 220. doi: 10.4172/21577625.1000220 .

[13] Matthew, N. K., Shuib, A., Ramachandan, S. and MohammadAfandi, S. H. (2019). Economic Valuation Using Travel Cost Method in Kilim Karst Geoforest Park, Langkawi, Malaysia. Journal of Tropical Forest Science 31 (1): 78-89.

[14] Hanley, N. and Barbier, E. B. (2009). Pricing nature: costbenefit analysis and environmental policy. Edward Elgar Publishing.

[15] Tietenberge, T. and Lewis, L. (2018). Environmental and Natural Resources Economics, 11th Edition. Routledge, New York, USA.

[16] Parsons, G. R. (2003). The travel cost model. In A Primer on Non-market Valuation (pp. 269-329). Springer.

[17] Besanko, D. and Braeutigam, R. R. (2011). Microeconomics. John Wiley \& Sons, New Jersey. 
[18] Bowles, S. (2009). Microeconomics: behavior, institutions, and evolution. Princeton University Press.

[19] Hellerstein, D. M. (1991). "Using Count Data Models in Travel Cost Analysis with Aggregate Data.” American Journal of Agricultural Economics 73 (3): 860-866.

[20] Zandersen, M. and Tol, R. S. (2009). A meta-analysis of forest recreation values in Europe. Journal of Forest Economics, 15 (1): 109-130.

[21] Sohngen, B., Lichykoppler, F., and Bielen, M. (1999). The value of Lake Erie beaches. Department of Agricultural, Environmental, and Development Economics. The Ohio State University.

[22] Ndichia, G. C. (2007). Advanced micro-economic theory (4th ed.), Bamenda: Maryland Publishers.

[23] Iorgulescu, F., Alexandru, F., Cretan, G. M., Kagitci, M. and Iacob, M.(2011). Considerations regarding the Valuation and Valorization of Cultural Heritage. Theoretical and Applied Economics, Volume XVIII, 12 (565), 15-32.

[24] Christie, M., Fazey, I., Cooper, R., Hyde, T. and Kenter, J. O. (2012). An evaluation of monetary and non-monetary techniques for assessing the importance of biodiversity and ecosystem services to people in countries with developing economies. Journal of Ecological Economics, 83: 67-78.

[25] Anderson, D. M (2010). Estimating the Economic value of ice climbing in Hyalite Canyon: An application of travel cost count data models that account for excess zeros. Journal of Environmental Management 91: 10-12.

[26] Turner, R. K, Georgiou, S. and Fisher, B. (2008). Valuing Ecosystem Services: The Case of Multi-functional Wetlands. UK: Cromwell Press.

[27] Zin, W. S., Suzuki, A., Peh, K. SH. and Gasparatos, A. (2019). Economic Value of Cultural Ecosystem Services from Recreation in Popa Mountain National Park, Myanmar: A Comparison of Two Rapid Valuation Techniques. Land 20198 194; doi: 10.3390/land8120194.

[28] Varian H. R. (2010). Intermediate Microeconomics: A modern approach. New York: W. W Norton \& Company.

[29] Muryani and Probugatt, (2016). An Economic Valuation of Ecotourism Using Travel Cost Method Approach. International Journal of Research in Advent Technology, Vol. 4, No. 12, December 2016 E-ISSN: 2321-9637.

[30] Carr, L., and Mendelsohn, R. (2003). Valuing coral reefs: a travel cost analysis of the Great Barrier Reef. Ambio, 32 (5), 353-357.

[31] Navrud, S. Å., and Mungatana, E. D. (1994). Environmental valuation in developing countries: the recreational value of wildlife viewing. Ecological economics, 11 (2), 135-151.

[32] Yrgalem, D. and Mekonnen, B. (2019). Recreational Use
Value of Lakes; An Application of Travel Cost Method; A Case of Lake Ziway. International Journal of Environmental Sciences and Natural Sciences 19 (4). DOI: 10.19080/IJESNR.2019.19.556018.

[33] Twerefou, D. K and Ababio, D. K. A. (2012). An economic valuation of the Kakum National Park: An individual travel cost approach. African Journal of Environmental Science and Technology Vol. 6 (4), 199-207.

[34] Prabugati, G.(2016). An Economic Valuation of Ecotourism Using Travel Cost Method Approach. International Journal of Research in Advent Technology, Vol. 4, No. 12.

[35] Mendes, I. and Proenca, I. (2005). Estimating the Recreation Value of Ecosystems by Using A Travel Cost Method Approach. Working Paper Presented in the Permanent Seminar of the Department of Economics $24^{\text {th }}$ May 2005, University of Lisbon.

[36] Khan, H. (2004). Demand for Eco-Tourism: Estimating Recreational Benefits from the Margalla Hills National Park in Northern Pakistan. South Asian Network for Development and Environmental Economics (SANDEE). Working Paper No. 5-04.

[37] WWF (2013). The Economic Value of Virunga National Park.

[38] Abinash, B. and Ritwik, M.( 2012). Application of Travel Cost Method to Assess the Pricing Policy of Public Parks: The Case of Kaziranga National Park. Journal of Regional Development and Planning, Vol. 1, No. 1.

[39] Stoeckl, N. and Mules, T. (2006). A travel cost analysis of the Australian Alps. Tourism Economics, 2006, 12 (4), 495-518.

[40] Liam, C. and Robert, M. (2003). Valuing Coral Reefs: A Travel Cost Analysis of the Great Barrier Reef. Ambio Vol. 32 No. 5.

[41] Tanzania National Parks. [http://www.tanzaniaparks.go.tz] site visited on 22/08/2020.

[42] Mehmet, P and Mustafa, F. T (2006). "Estimation of Recreational Use Value of Forest Resources by Using Individual Travel Cost and Contingent Valuation Methods (Kayabasi Forest Recreation Site Sample). Journal of Applied Sciences, 6 (1) 1-5.

[43] Bergstrom, J. C. and Cordell, H. K (2018). An Analysis of the Demand for and Value of Outdoor Recreation in the United States, Journal of Leisure Research, 23 (1): 67-86.

[44] Yrgalem, D. and Mekonnen, B. (2019). Recreational Use Value of Lakes an Application of Travel Cost Method: A Case of Lake Ziway. International Journal of Economy, Energy and Environment, 4 (3): 56-62.

[45] Grilli, G., Landgraf, G., Curtis, J. and Hynes, S. (2018). A travel cost evaluation of the benefits of two destination salmon rivers in Ireland. Journal of Outdoor Recreation and Tourism, 23: $1-7$. 